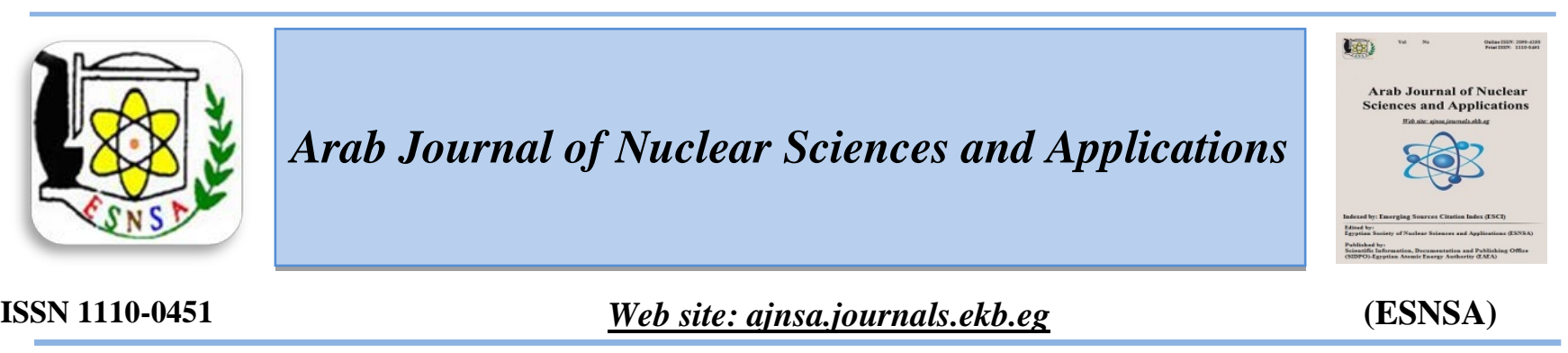

\title{
Metal ions Release in Saliva from Fixed Orthodontic Appliances: A Systematic Review
}

\author{
Radwa Sallam ${ }^{1^{*}}$ \\ ${ }^{1}$ Health Radiation Research Department' National Centre for Radiation Research \\ and Technology (NCRRT), Atomic Energy Authority, Cairo, Egypt,
}

\begin{abstract}
Received $28^{\text {th }}$ Feb 2020 Accepted 6 ${ }^{\text {th }}$ Apr 2020

Standard Orthodontic intervention involves the use of brackets, bands and arch wires. Brackets used in orthodontic treatment provide the means to transfer force to the teeth using the arch wire. Biodegradation of different typ orthodontic brackets might lead to metal ion release . Nickel (Ni) and chromium $(\mathrm{Cr})$ containing alloys are present in the manufacture of most of the orthodontic appliances. The increase of nickel and/or chromium ions release could result in heath hazardous effects. Analysis of the released metal ions was performed through mass spectroscopy, atomic absorption spectroscopy. The aim of this study is to systematically assess the release of metal ions with fixed orthodontic appliances using ceramic brackets. Electronic searches will be performed in two databases (PubMed, Cochrane). The PubMed, identified 29 studies, four of them met the inclusion criteria. In conclusion, although these studies are limited, this systematic review can state that the release of metal ions in patients with fixed orthodontic appliances is in measurable amounts that are considered to be safe. In addition, there are no differences in the release of salivary ions regardless of the bracket type used.
\end{abstract}

Keywords: Metal ions release / Ceramic brackets / Metallic brackets

\section{Introduction}

\section{a. Rationale:}

Standard Orthodontic intervention, involves the use of brackets, bands and arch wires. Nickel (Ni) and Chromium (Cr) containing alloys are present in the manufacture of most of the orthodontic appliances, Since different metal alloy combinations are used for prolonged periods in orthodontic patients, special consideration with regard to their biocompatibility should be given (15)
Manufacturing process together with environmental factors result in corrosion of orthodontic appliances. Consequently, metal ion release occurs. (6) The oral cavity contains many factors which enhance the biodegradation of orthodontic appliances. The change of $\mathrm{pH}$ and temperature, the enzymatic and microbial activity, and the various chemicals that come in contact with oral cavity through food and drink are all corrosion conductors. Furthermore, Saliva acts as an electrolyte which further facilitates metal ion conduction $(7,8)$.

Corresponding author: radwasallam36@gmail.com

DOI: 10.21608/ajnsa.2020.24817.1329

(C) Scientific Information, Documentation and Publishing Office (SIDPO)-EAEA 
Analysis of released metal ions was performed through mass spectroscopy, ICP-AES, atomic absorption spectroscopy. The average dietary intake of Nickel and Chromium is $200-300 \mu \mathrm{g}$ /day and $50-200 \mu \mathrm{g} /$ day respectively. The increase of Nickel (Ni) and Chromium (Cr) ion release, could result in hazardous conditions. Nickel can be an allergen or carcinogenic and act mutating substance by causing alteration in DNA. On the other hand, high doses of chromium may result in insomnia $(10,11)$

Over the last several decades, studies have been conducted on metal ion release using different types of brackets with different arch wires. However, studies evaluating the release of metal ions in saliva are controversial. Some studies found an increase in salivary nickel or chromium concentrations (1 ) .On the other hand, other studies reported no increase in salivary levels of nickel and chromium in patients after installment of orthodontic appliances (10) (12-18).

Ceramic brackets are popular as an esthetic appliance in the field of orthodontics. The use of ceramic brackets with or without metal slot with different types of wires is increasing day by day. (19) Hence, its biocompatibility and metal ion release should be considered. The aim of this review is to evaluate the release of metal ions during fixed orthodontic treatment using ceramic brackets.

\section{b. Objectives:} PICO Question

\begin{tabular}{|l|l|}
\hline Question & $\begin{array}{l}\text { In patients with fixed orthodontic } \\
\text { appliances, will ceramic brackets } \\
\text { compared to metallic brackets } \\
\text { result in metal ion release? }\end{array}$ \\
\hline Population & $\begin{array}{l}\text { Patients with Fixed orthodontic } \\
\text { appliances }\end{array}$ \\
\hline Intervention & Ceramic brackets \\
\hline Comparator & Metallic brackets \\
\hline Outcome & Release of metal ions \\
\hline
\end{tabular}

\section{Materials and Methods:}

a. Eligibility criteria:

\section{Inclusion Criteria:}

- Randomized Controlled Trials, observational studies and in vitro studies.

- Fixed orthodontic appliances

- Studies conducted using artificial saliva

- Studies conducted using oral environmental conditions

- Release of nickel and chromium ions

- Amount of ions released measured in $\mu \mathrm{g} / \mathrm{l}$ or $\mathrm{ppb}$

\section{Exclusion Criteria}

- Studies were done in acidic environment

- Metal ions release using other units

- Other biological changes

- Medically compromised patients 


\section{b. Search}

\begin{tabular}{|c|l|c|c|}
\cline { 3 - 4 } \multicolumn{2}{l|}{} & Pub Med & Cochrane \\
\hline PICO Item & \multicolumn{1}{c|}{ Date } & $10 / 9 / 2019$ & $10 / 9 / 2019$ \\
\hline Population & $\begin{array}{l}\text { Patients with fixed orthodontic } \\
\text { appliances } \\
\text { Fixed } \\
\text { Orthodontic } \\
\text { appliances[Text word] } \\
\text { Fixed orthodontic appliances } \\
\text { [Mesh Terms] }\end{array}$ & 2014 & 534 \\
\hline Intervention & $\begin{array}{l}\text { Ceramic brackets } \\
\text { Ceramic brackets[Mesh Terms] } \\
\text { Ceramic brackets[Text word] }\end{array}$ & 1026 & 41 \\
\hline Comparator & $\begin{array}{l}\text { Metallic brackets } \\
\text { Metallic brackets[Mesh Terms] } \\
\text { Metallic brackets[Text word] }\end{array}$ & 1407 & 26 \\
\hline & \multicolumn{1}{c}{ Combined Search } & 18 & 4 \\
\hline
\end{tabular}


Records identified through database searching $(n=22)$

Records after duplicates removed

Additional records identified through other sources $(n=8)$

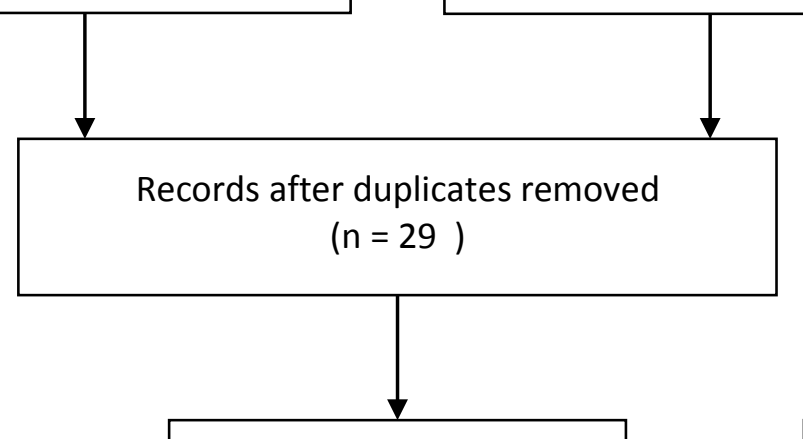

\begin{tabular}{|c|c|}
\hline $\begin{array}{c}\text { Records screened } \\
(\mathrm{n}=29)\end{array}$ & $\begin{array}{c}\text { Records excluded } \\
(\mathrm{n}=20)\end{array}$ \\
\hline Full-text articles assessed & $\begin{array}{c}\text { Full-text articles excluded, } \\
\text { with reasons } \\
(\mathrm{n}=0)\end{array}$ \\
\hline
\end{tabular}

$\frac{\text { 엉 }}{\frac{0}{0}}$ for eligibility $(n=4)$

Studies included in qualitative synthesis

$$
(n=4)
$$


Table 1

\begin{tabular}{|c|c|c|}
\hline Author (year) & Study Type & Results \\
\hline $\begin{array}{l}\text { Retamoso } \\
\text { al.,2012 }\end{array}$ & In vitro study & $\begin{array}{l}\text { Monocrystalline ceramic brackets had good } \\
\text { biocompatibility. On the other hand, polycrystalline ceramic } \\
\text { brackets with metal slots demonstrated some toxic effects } \\
\text { due to nickel ion release }\end{array}$ \\
\hline $\begin{array}{l}\text { Khamees } \\
\text { al.,2014 }\end{array}$ & In vitro study & $\begin{array}{l}\text { Nickel, and Chromium ions released from combination of } \\
\text { monocrystalline brackets with different arch wires } \\
\text { immersed in artificial saliva at different duration, Both } \\
\text { nickel and chromium ions increase with increasing intervals }\end{array}$ \\
\hline $\begin{array}{l}\text { Jithesh } \\
\text { al.,2015 } 233)\end{array}$ & In vitro study & $\begin{array}{l}\text { Nickel ion release from the recycled stainless } \\
\text { steel brackets is higher compared to metal slot ceramic } \\
\text { bracket. Hence, recycled stainless steel brackets should not } \\
\text { be used for nickel allergic patients. }\end{array}$ \\
\hline $\begin{array}{l}\text { Jurela } \\
\text { al.,2018 }\end{array}$ & In vivo study & $\begin{array}{l}\text { The salivary level of t nickel ion increased after installment } \\
\text { of metallic brackets while, it decreased in ceramic bracket. } \\
\text { On the other hand, chromium ions significantly decreased } \\
\text { of orthodontic appliances, regardless of bracket type, which } \\
\text { was used. } \\
\text { There were no significant differences in salivary levels of } \\
\text { nickel and chromium between the patients with metallic } \\
\text { and those with ceramic brackets. }\end{array}$ \\
\hline
\end{tabular}

\section{Results:}

The PubMed, Cochrane database and hand search identified 83 studies. No additional search in other database was performed.

From 29 identified studies, four met the selection criteria. The description of the studied materials is mentioned in Table (1)

\section{Discussion:}

In this systematic review, only four studies met the eligibility criteria. The scarcity of the consistent studies underlines the lack of scientific evidence on metal ion release from the ceramic brackets .Low number of included studies in addition to variation in study designs and /or methodologies enabled standardized evaluation. Consequently, comparisons with other studies were limited. Moreover, meta-analysis was impeded. The present review included both in vivo and in vitro studies. In-vivo studies are extremely beneficial in explaining how orthodontic materials react in their actual functioning environment however difficult to standardize owing to many factors that cannot be under experimental control ${ }^{(8)}$.On the other hand, despite in vitro studies lack the simulation of the oral cavity, in vitro studies are valuable because they are performed under controlled laboratory conditions. (9) The rationale of the current combined in vivo - vitro study, was to evaluate the metal ion release from ceramic brackets from both laboratory and clinical perspectives, identify consistencies and inconsistencies between in vitro and in vivo studies. Moreover, to find out whether evidence from these studies lies on the same direction.

Ceramic brackets are produced from alumina, either as monocrystalline or polycrystalline. ${ }^{(20)}$ Three in vitro studies evaluated metal ion release from both polycrystalline and monocrystalline ceramic brackets immersed in artificial saliva.

Retamoso et al. ${ }^{(21)}$ evaluated various orthodontic brackets and reported that monocrystalline ceramic brackets had good biocompatibility. However, polycrystalline ceramic brackets with metal slots demonstrated some toxic effects due to nickel ion release.

Khamees et al. ${ }^{(22)}$ measured nickel and chromium ions release from monocrystalline ceramic brackets 
and stainless steel brackets in combination with different arch wires. Regarding, monocrystalline brackets nickel and chromium increase in combination stainless steel, nickel-titanium .The greatest concentration of nickel ions release was during the first week .However, the release of chromium increase with intervals until reach the greatest level in the third week. As for stainless steel brackets, both nickel and chromium ions increased with increase intervals.

Jithesh et al. ${ }^{(23)}$ studied nickel ion release from ceramic bracket with metal slot, conventional and recycled stainless steel brackets and reported that Metal slot ceramic bracket release is significantly less in case of nickel ions compared to other groups.

On the other hand, one in vivo study was carried out by Jurela et al., ${ }^{(24)}$ who compared salivary levels of nickel and chromium ions prior to and six months after the installment of metallic or ceramic brackets. They pointed out that there was no difference in baseline salivary concentrations of any of the studied electrolyte between patients with metallic and non-metallic braces. In addition, they found decreased chromium levels and no change in salivary nickel concentration six month after the insertion of orthodontic appliance. To reiterate, the studies selected for the present systematic review indicate low release of metal ions from ceramic brackets in comparison to metallic brackets. In addition quantities of metal released ions were below the toxic levels and did not exceed the daily intake.

The strength point of this review is revealed through considering evidence from both in vitro and in vivo studies. However, a number of limitations is found, especially with regard to the limited studies and the lack of standardization. Further studies with more rigorous methods, such as randomized, controlled clinical trials will be advantageous.

\section{Conclusions}

Until now, only a few studies on the evaluation of metal ions release in the oral cavity using ceramic brackets were conducted. This systematic review can support the concept that the release of metal ions in patients with fixed orthodontic appliances is in measurable amounts are considered safe. In addition, there is no difference in the release of salivary ions regardless of the electrolyte between patients with metallic and non-metallic braces.

\section{Recommendation}

Analyzing the results of the study, it seems that there is a necessity to standardize procedures, with detailed methodology provided. In addition, more clinical trials with long-term follow up periods are recommended.

\section{References}

1. Petoumeno E, Kislyuk $M$, Hoederath $H$, Keilig L, Bourauel C, Jäger A. (2008) Corrosion susceptibility and nickel release of nickel titanium wires during clinical application. J Orofac Orthop 69(6),411-23.

2. Haddad AS , Tortamano A , Souza AL , Oliveira PV (2009). An in vitro comparison of nickel and chromium release from brackets. J Braz Oral Res. 23(4),399-406.

3. Amini F, Jafari A, Amini P , Sepasi S. Metal ion release from fixed orthodontic appliances - an in vivo study(2012) European Journal of Orthodontics 34,126-130.

4. Toy E, Malkoc S, Corekci B, . Bozkurt BS, Hakk SS (2012). Real-time Cell Analysis of the Cytotoxicity of Orthodontic Brackets on Gingival Fibroblasts..J Appl Biomater Funct Mater 12 (3),248-255.

5. Furlan TP, Barbosa JA, Basting RT (2018) . Nickel, copper, and chromium release by CuNi-titanium orthodontic archwires is dependent on the $\mathrm{pH}$ media. $J$ Int Oral Health 10:224-8.

6. -Nayak RS, Khanna B, Pasha A, Vinay K, Narayan A, Chaitra K. (2015) Evaluation of Nickel and Chromium Ion Release During Fi xed Orthodontic TreatmentUsing Inductively Coupled Plasma-Mass Spectrometer: An In Vivo Study.J Int Oral Health 7(8),14-20.

7. Eliades T, Bourauel C. (2005) Intraoral aging of orthodontic materials: The picture we miss and its clinical relevance. $A m \mathrm{~J}$ Orthod Dentofacial Orthop 127(4),403-12.

8. Hafez HS, Selim EM, EidFK, Tawfik WA, Emad AA , Mostafa YA. (2011) Cytotoxicity, genotoxicity and metal release in patients with fixed orthodontic appliances: A longitudinal in vivo study. Am J Orthod Dentofacial Orthop 140 ,298-308.

9. Pravinya S , Dhanraj M, Ashish R. (2018) J Release of titanium ions in titanium alloys 
used in dentistry - A systematic review. $J$ Drug Invention Today 10 (4) ,536-541

10. Sahoo N, Kailasam V, Padmanabhan S, Chitharanjan $\mathrm{AB}(2011)$. In-vivo evaluation of salivary nickel and chromium levels in conventional and self-ligating brackets. Am J Orthod Dentofacial Orthop 140(3),340-5

11. -Dwivedi A, Tikku T, Khanna R, Maurya RP, Verma G, Murthy R C (2015)

12. Release of nickel and chromium ions in the saliva of patients with fixed orthodontic appliance: An in-vivo study. Natl J Maxillofac Surg 6(1),62-66.

13. - Kerosuo H, Moe G, Hensten-Pettersen A(1997) Salivary nickel and chromium in subjects with different types of fixed orthodontic appliances. Am J Orthod Dentofacial Orthop. 111(6),595-8.

14. - Kocadereli L, Ataç PA, Kale PS, Ozer $\mathrm{D}(2000)$ Salivary nickel and chromium in patients with fixed orthodontic appliances.J Angle Orthod 70(6),431-4.

15. - Ağaoğlu G, Arun $T$, Izgi $B$, Yarat A (2001) Nickel and chromium levels in the saliva and serum of patients with fixed orthodontic appliances. Angle Orthod. 71(5),375-9.

16. Eliades T, Trapalis C, Eliades G, Katsavrias E(2003) Salivary metal levels of orthodontic patients: a novel methodological and analytical approach. Eur J Orthod 25(1),1036.

17. - Yassaei S, Dadfarnia S, Ahadian H, Moradi F(2013) Nickel and chromium levels in the saliva of patients with fixed orthodontic appliances. Orthodontics (Chic) 14(1),76-81.

18. Amini F, Harandi S, Mollaei M, Rakhshan V (2015) Effects of fixed orthodontic treatment using conventional versus metal-injection molding brackets on salivary nickel and chromium levels: a double-blind randomized clinical trial. Eur J Orthod 37(5),522.

19. . Gölz L, Knickenberg AC, Keilig L, Reimann S, Papageorgiou SN, Jäger A (2016) Nickel ion concentrations in the saliva of patients treated with self-ligating fixed appliances: a prospective cohort study. J Orofac Orthop. 77(2), 85-93.

20. 20-Priyanka , A, Felicita S, Leelavathi L(2018) Complications of ceramic brackets with the challenge of bonding attachments on teeth restore Drug Invention Today 10 (3) ,3411-3416.

21. - Patel D , Mehta F, Mehta N (2014) .Aesthetic Orthodontics : An Aesthetic Orthodontics : An Overview. Orthodontic Journal of Nepal, 3(2):38-43.

22. -Retamoso LB, LuzTB, Marinowic DR, MachadoDC, Luciane Macedo De MenezesMD, FreitasMP, Silva Oshima HM .(2012) Cytotoxicity of esthetic, metallic and nickel-free orthodontic brackets: Cellular behavior and viability American journal of orthodontics and dentofacial orthopedics: official publication of the American Association of Orthodontists, its constituent societies, and the American Board of Orthodontics 142(1),70-4 .

23. Khamees A.S and Al-Joubori S.K. (2014) Comparison of metal ions release and corrosion potential from different bracket archwire combinations (An in vitro study).$J$ Bagh Coll Dentistry 26(1),171-179.

24. -.Jithesh C, Venkataramana V, Penumatsa N, Reddy SN, Poornima KY, Rajasigamani K (2015) .Comparative evaluation of nickel discharge from brackets in artificial saliva at different time intervals. $J$ Pharm Bioallied Sci. 7(2), 587-93.

25. - Jurela A, Verzak Ž, Brailo V, Škrinjar I, Sudarević $\mathrm{K}$, Janković B. Salivary Electrolytes in Patients with Metalli c and Ceramic Orthodontic Brackets(2018) Acta Stomatol Croat.52(1),32-36. 